\title{
Analysis on the Development of Modern Smart Home Industry and Cloud Computing Technique with the Influence on Transforming the Internet Startup Orientation
}

\author{
Ya Liu and Chun Yang \\ School of Business, Changzhou University, Changzhou 213164, China
}

\begin{abstract}
In this paper, we analyze the development of modern smart home industry and cloud computing technique with the influence on transforming the Internet startup orientation. Internet of things actually have long put forward the concept of smart home, after years of development of this technology has been more and more attention, this technology has obtained the country vigorously promoted. In our research, we propose the following aspects of the new perspectives. (1) We review the state-of-the-art smart home systems. We discuss the HIPERLAN2 technology, Ultra wideband technology and blue-tooth technology to show the core techniques of the smart devices. Because of the data center in place is restricted, we can specifically for the design of a product and make it suitable for household environment. (2) We demonstrate the modern could computing based techniques. Through the analysis of the current mainstream industry cloud infrastructure system and the research of the related academic achievements, we can see a cloud infrastructure is used by the physical resources into virtual resource pool, implementation of monitoring, scheduling management for upper applications and users in order to achieve flexibility for the purpose of computing and the storage resources. (3) Based on the introduction of the high-tech approaches, we analyze the development trend of the Internet of things and corresponding technologies with discussion of transforming the Internet startup orientation and direction. In the experimental analysis part, we statistically show the trend of the technique, enterprise and the combined development. In the future, we will review more literature to optimize the current methodology.
\end{abstract}

Keywords: Smart Home Industry; Cloud Computing; Internet Startup Orientation; High-tech Enterprise; Cloud Service Platform; Intelligence Hard Devices; Internet of Things

\section{Introduction}

With the rapid development of economy, people's standard of living and improve their own quality, it puts forward higher requirements on living environment and the residential housing demand concept also has changed thoroughly, the information and network become the basic connotation of smart home. As smart home network technology and related wireless network technology platform, the development of smart home network has played a good role its core idea is to use radio instead of traditional cable which achieves personal information terminal intelligent interconnection with personalized home information network. With development of science and technology intelligence lives in the scope of more and more widely used, the earliest intelligent household is Bill Gates' house of the future. In gates if there is a guest in the home visit will wear special electronic brooch, through brooch can automatically record the guest's related information and then send information to the central controller, a computer through a comprehensive analysis of brooch to send this information to set the pattern of the related equipment, such as lighting, acoustics, air conditioning and so on. Through the simple action can realize full automatic setting of human nature. Internet of things actually have long put 
forward the concept of smart home, after years of development of this technology has been more and more attention, this technology has obtained the country vigorously promoted. But due to some technical limitations, so was not widely spread in the market nor also did not like the expected effect of depth to the homes of ordinary people, in the development process of intelligent household encountered great obstacles. But in recent years with development and popularization of intelligent mobile terminal, $3 \mathrm{G}$ and $4 \mathrm{G}$ network is widely used the key technologies of Internet of Things for the smart home created the bigger development space and make the Internet of things intelligent household have the opportunity to leave ordinary people home. Under the basic environment of smart home both in technology and quality has been further development. With all kinds of new technology constantly emerging, smart home is in the continuous development of a dynamic change. In the following figure one, we show one of the stateof-the-art smart home systems as the demonstration.

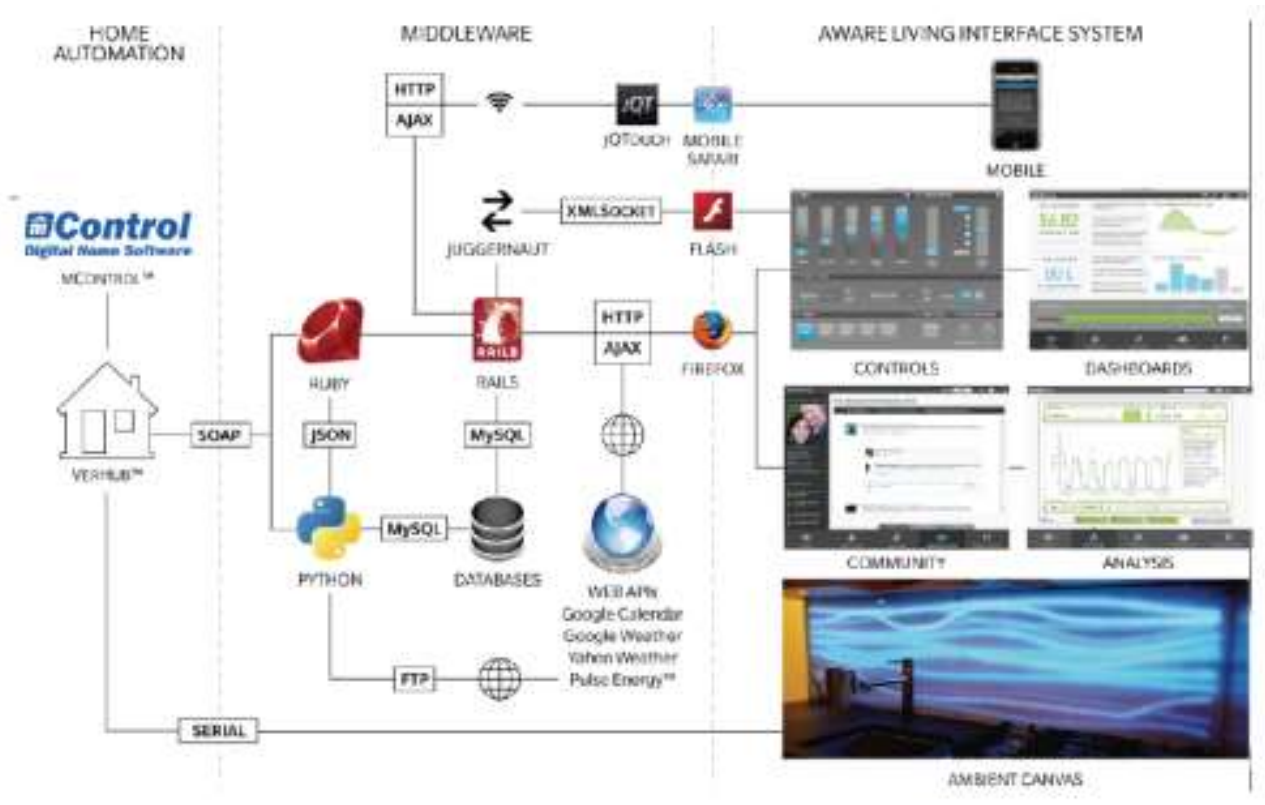

Figure 1. The Popularly Adopted Modern Smart Home System

The definition of cloud computing and service is numerous which is widely agreed that the cloud computing is the development of distributed processing, parallel processing and grid computing or the commercial implementation of the concept of the computer science. Cloud computing is a kind of mode of delivery and use of resources, to obtain the resources needed to apply through the network. Cloud computing will be calculated from the client terminal on the "cloud", as an application provides to the user via the Internet by distributed computing technologies such as completed jointly by multiple computers. Users only care about the application of the function, application and don't care about the realization way of realization of the application and maintenance done by the provider, the user chooses according to their own needs corresponding application. Cloud computing is not a tool or architecture but a way of calculation. The cloud service includes the following techniques. (1) Huge amounts of data management technology. The cloud computing needs to be distributed a vast amount of data processing and therefore, the data management technology must be able to efficiently manage large amounts of data. (2) Huge amounts of data storage technology. Cloud computing system is composed of a large number of servers, to serve a large number of users at the same time, so the cloud computing system with method of distributed storage to store data which make better use of redundant storage reliability of the data. (3) The programming model. Strict of programming model of the cloud computing environments of 
programming is very simple. It is the graphs model will execute breaking them down into Map and Reduce, first through the Map program isn't related to divide data into blocks, assigned to a large number of computer processing to achieve the effect of distributed computing and again through Reduce program will collect the output results. In the Figure 2 , we illustrate the cloud service platform.

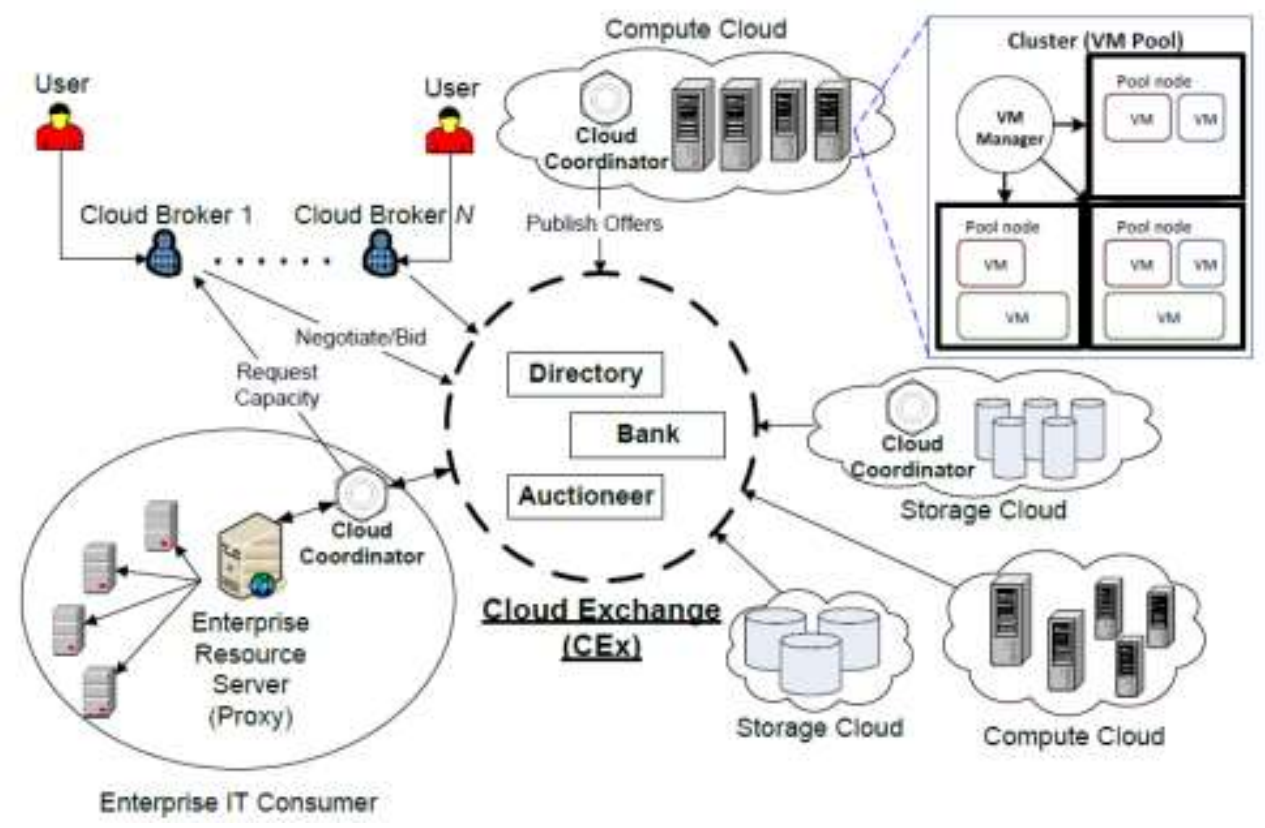

Figure 2. The Modern Cloud Service Platform for High-tech Enterprise

The Internet has become the world's most core infrastructure and the source of economic growth with the initiator of a new industry and it vigorously promotes the healthy and orderly development of the Internet industry which is the important measures to implement elements drive to innovation drive transition. Explore the new mode of Internet industry investment and set Internet industry investment fund, to break the path dependence overseas financing to promote and standardize the healthy development of the Internet industry and reduce Internet industry network information security risks has important and far-reaching significance.

To solve the mentioned challenges, in this research article, we propose our novel idea on the development of modern smart home industry and cloud computing technique with the influence on transforming the Internet startup orientation. The paper is organized as follows. In the Sections 2, we demonstrate state-of-the-art techniques of the smart home and its basic development trend for commercial usages. In the Sections 3, we illustrate the principles of the cloud computing technique and the primary applications. In the Section 4, we summarize the large-scale trend of the Internet, IOT and smart devices with the discussion of transforming the Internet startup orientation. In the Section 5, we experimentally simulate the popular and best performed technique adopted by the enterprises with the visual trend of startup direction. In the Section 6, we summary our work and finalize our prospect.

\section{The State-of-the-art Smart Home Systems}

Smart home is also called the smart home, it is the use of advanced computer technology, network communication technology, intelligent control technology with sensor technology, integrated wiring technology, through the information in the 
household and the control center and the associated with the household life security, environmental control, communications, intelligent home appliances and other subsystems organically combines the complex system. In the Figure 3 we should be basic sensor distribution of the smart home.

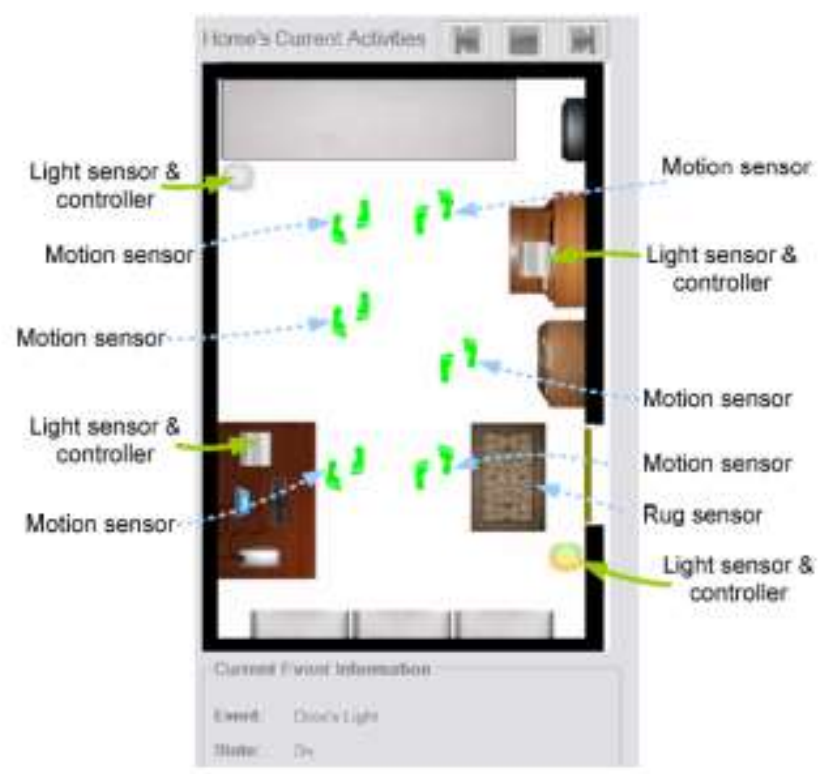

\section{Figure 3. The Basic Sensor Distribution of the Smart Home}

Smart home controller is the core of the whole system as the family gateway to connect the internal network and external network and provide the function of remote monitoring for the extranet. It is an embedded web server, internally uses the wireless communication, external using Ethernet and the core GPRS communication, users connected to the Internet through the computer mobile phone log in the Web primary server, we can view or control of information appliances, curtains, lighting and room temperature family equipment, security equipment, etc. The core techniques adopted by the system is organized as the follows.

(1) HIPERLAN2 technology. It broke through the wireless network in use of spectrum, frequency points within the $5 \mathrm{GHZ}$ spectrum distribution and the frequency point and easier management rules which can make a large number of users to realize the high-speed communication. The data communication between mobile terminal and access points through signaling links are set up in advance, access to monitor the surrounding of the wireless channel, automatically choose the idle channel frequency distribution, eliminates the requirement for the frequency planning and makes the system simple.

(2) Ultra wideband technology. Ultra wideband technology is the kind of time domain base communication technology, wireless communications technology is very different with the above, it does not use the carrier of the implementation is far better than other wireless technology is simple and can be integrated in a relatively low-cost chip with the power of consumption is extremely low and average power level for modulation of the pulse signal spectral density is extremely low, has the very high processing gain, its weak radio pulse signal scattered in broad frequency band, the noise, even lower than the general equipment has the very high security performance.

(3) Bluetooth technology. Bluetooth system can not only realize the point-to-point (P2P) connections, it can also realize point to multipoint connection. In the case of a point on the multipoint connection and the channel is shared by several blue- 
tooth equipment, formed covered each other to form the so-called distribution network.

In specific implementation process, because the data center in the whole network appear as network center, so we can set up the communications equipment as the data center separate arrangement at home in the center position. Because of the data center in place is restricted, we can specifically for the design of a product, make it suitable for household environment. The position of the control center for the users, for users at home often is in not certain state, so we set the user control center to terminal equipment. Need to use the direct communication equipment via USB is inserted into the tablet, establish connection with data center. Similarly, every household appliance control end is set to the terminal device, when the need to control the home appliances start the corresponding terminal equipment after joining the network can manage the home appliance equipment. The Figure 4 show the chips structure for the system.

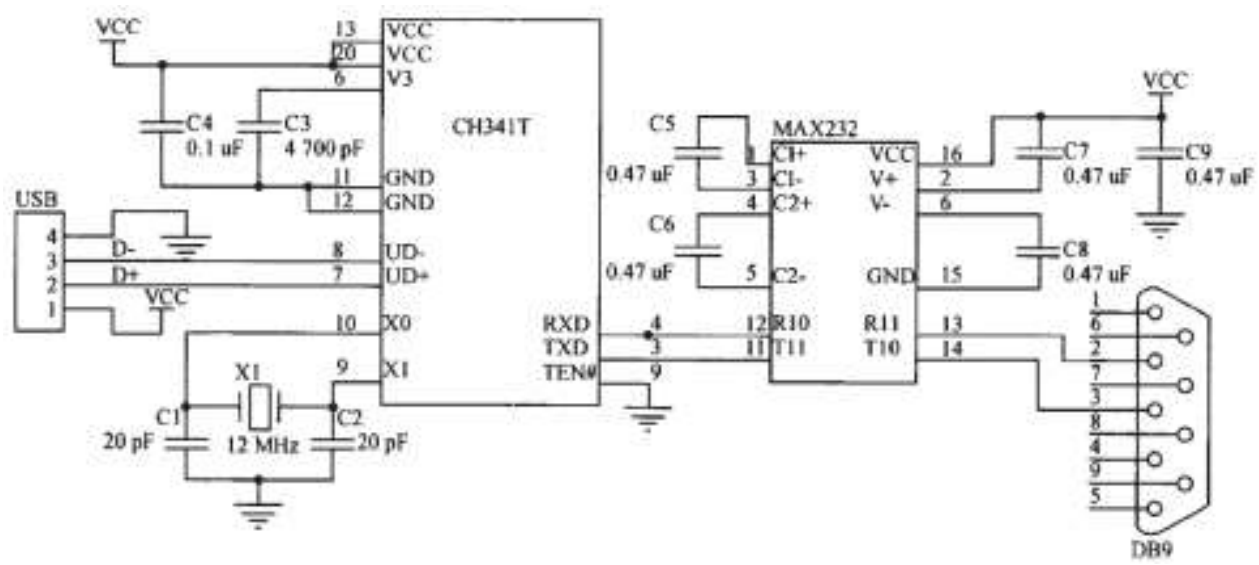

Figure 4. The Chips Design for the Mentioned Smart Home Control Board

\section{The Principles of the Cloud Computing Technique}

The rapid development of cloud computing with the market demand and is closely related to the powerful technical support. First of all, with the rapid development of IT industry, the IT operators have formed their respective large server cluster. How to realize re-engineering of existing cluster to reduce operational costs and improve efficiency becomes the primary problem of operators to consider. In addition, the rapid development of the IT market is also require the operators to provide a more stable and efficient service. Secondly, the continuous development of the distributed system, virtualization technology is perfect that makes it more possible to service cluster performance of rapid ascension. In general, we separate structure of the cloud system into following parts. (1) Refers to physical structures, physical equipment for basic deployment of cloud infrastructure and supporting environment and effect for the cloud infrastructure provide the basic material resources and maintain reliability of physical device. (2) Data layer is refers to customer data of cloud infrastructure runs within the level of the basic operation and management. Development environment is a service to provide which refers to the basic application in the form of service development and deployment platform for thirdparty developers. The data layer contains two main parts, data processing and data management. (3) Management is a level of abstraction of the entire cloud infrastructure. It to monitor cloud infrastructure of all kinds of resources, according to the actual load condition and the resource management and scheduling according to the requirements of the upper to rapid deployment of resources to ensure that the cloud infrastructure to run efficiently. (4) Service layer refers to call cloud infrastructure for the upper cloud 
computing and storage resources reserve and the interface to the user using the cloud infrastructure of computing and storage resources to provide interactive interface. Service layer holds effect on infrastructure efficiency embodied in the service layer on the universality of all kinds of interface.

Ordinary proxy mechanism lack of intelligence under network environment, for first visit to the multi-source resources characteristic estimation and access path optimization, need the multi-source access to resources in cloud fusion model constructed features for information extraction. The formula 1 defines the primary model.

$$
f\left(x_{1}, x_{2}\right)=r_{1} x_{1}\left(1-\frac{x_{1}}{N_{1}}-\sigma_{1} \frac{x_{2}}{N_{2}}\right)=0
$$

Build the cloud network model of multi-source access to resources and the heuristic cloud computing algorithm based on genetic algorithm for multiple source characteristics of access to resources for the optimization design of the minimum variance estimation. The criteria of a measurement standard could be summarized as the follows.

$$
d(m, n)=\sqrt{\left(x_{i}-x_{j}\right)^{2}+\left(y_{i}-y_{j}\right)^{2}}
$$

With the development of cloud computing and virtualization technologies, traditional data center architecture has gradually become the important problem for the further development of cloud computing. The current data center is a typical architecture of the Ethernet adopts the tree structure of layer three switching. It is composed of layer, convergence layer and the core layer people. Among them, pick up one layer with low cost and high density of equipment to complete the user after the function of the network; Convergence layer is responsible for the gathering more access layer switches, and connect the upper core layer; Core layer, there is a high speed data transfer rate of exchange which is the receiving of the network traffic and convergence. The measure the effectiveness and robustness of the cloud computing system, we could use the fuzzy set theory to finalize the steps denoted as the formula 3.

$$
u_{1} \rightarrow f\left(u_{i}\right)=\left\{p_{i 1}, p_{i 2}, p_{i 3}, \ldots, p_{i n}\right\} \in F(m)
$$

We will first introduce the concept of entropy in information theory, is used to measure the uncertainty of the things, that is, greater the amount of information, the less the uncertainty, the smaller the entropy; On the contrary, the smaller the amount of information, the greater the uncertainty and the greater the entropy. The definition is shown as the formula 4.

$$
H\left(p_{1}, p_{2}, p_{3}, \ldots, p_{n}\right)=-k \sum_{i=1}^{n} p_{i} \ln p_{i}
$$

Cloud computing applications in a lot of distribution and the gathering data to make the traditional TCP protocol data congestion can occur easily, such as a node sends a request to multiple nodes, and the multiple nodes after receipt of a request to respond almost at the same time and then multiple nodes to the same server at the same time return the TCP data flow which will lead to temporary congestion phenomenon. In the following Figure 5 , we show the general data storage for the cloud computing. 


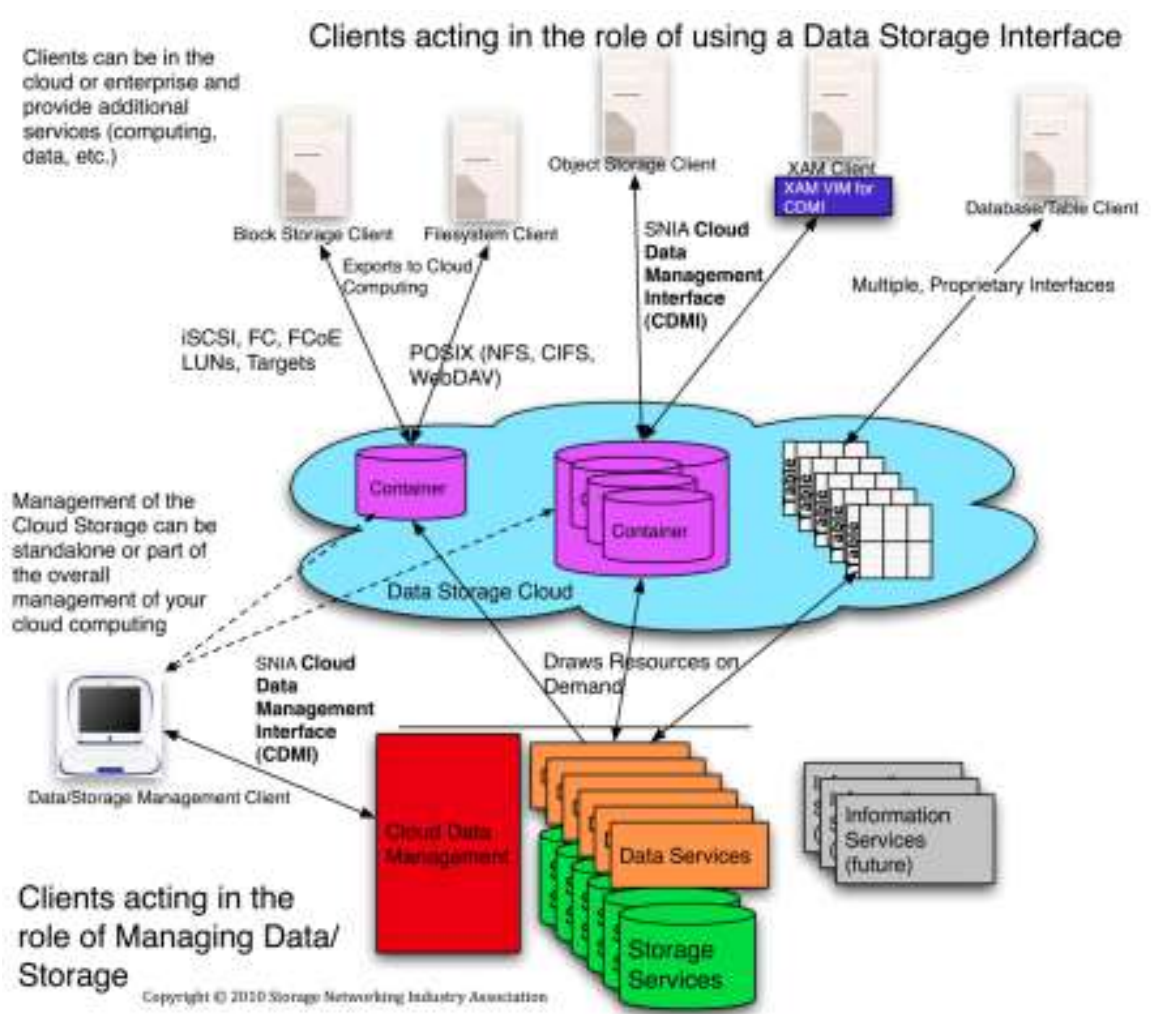

Figure 5. The General Data Storage for the Cloud Computing

\section{The Transformation of Startup Orientation with High-tech Elements}

With the continuous development of network technology and the popularity of the Internet growing and at the same time on the Internet is becoming more and more widely. Internet communication application is an important part of Internet application link, a new type of Internet communication applications also began to appear and gradually expand. New Internet communication will be different from the traditional communications applications which have the richer connotation to realize the integration of communication, content and the application services. New Internet communication application is a new field that can be more humanized communication applications will be in the competition.

\subsection{The Development of the Internet and the IOT}

The Internet is rapid development on the basis of network communication incrementally. Due to the lack of the systematic design, Internet development initial period when the core development of Internet and its application to the existing scale, efficiency of the network, security, scalability, and innovation ability which is faced with many challenges.

$>$ Network security. As vast users with intelligent terminal access and interconnection. At the same time, along with the network attack trend of commercialization, interests. Internet security risk is increasingly prominent. At this stage, the development of technology and application, such as a cloud computing has also had Internet security new topic: not only displays in the application of cloud computing without boundary, liquidity triggered many new security issues and because the basic cloud computing application for users and information resources of high concentration are more likely to become the target of hackers. 
Network expansibility. Network expansibility, first of all, we show the address space extensibility. Any user with terminal pickup anytime and anywhere is basic condition of the development of Internet. Because the IPv4 address space is relatively narrow and the unbalanced allocation. Currently, IPv4 address resources depleted much of region. Based on IPv6 network address space can meet the longterm development of the Internet in future, but because of incompatibility between IPv4 and IPv6. Internet addressing space transformation will be a long and complicated process.

$>$ The innovation ability. Innovation is primary vitality of the Internet. Guided by the user experience of innovation is the main development direction of innovation of the Internet. In the future, a community, customized, personalized Internet applications will become mainstreams and efficient becomes basic requirement of innovation.

$>$ The network performance. The popularity of the Internet can help reduce the overall energy consumption of society, but also exist problem of high energy consumption of the Internet itself. For the long time. Extensive way of network operations and give priority to with incremental mode of network construction, led to the high energy consumption of the Internet seriously restricting the sustainable development.

The improvement of the mobile Internet environment effectively stimulated user demand, the user can at any time and at any place and any screen mobile Internet access and uses it in all kinds of business. At present, China's Internet business is growing rapidly, including the kinds of music, entertainment, information search and query, instant messaging, etc., in developed countries is growing rapidly in the business is entertainment application, news, social network and games, etc. For user preferences for the business, business providers are also developing different types of business, all kinds of business are changing constantly with user needs change. In Maslow's demand level, human needs can be divided into physiological needs, security needs and respect the demand level and the realization of self-worth demand level. The Figure 6 demonstrates the comparison of the Internet popularizing rate.

\begin{tabular}{|c|c|c|c|c|c|c|c|c|}
\hline & \multicolumn{4}{|l|}{$1997-8$} & \multicolumn{4}{|l|}{$2000-1$} \\
\hline & Continuibe uses & Drop-outs & Late adcoplen & Non-teens & Continuire users & Drop-outs & Late adopten & Non-users \\
\hline Frequency & 3074 & 832 & 2686 & 10,367 & 10,433 & 1817 & 3476 & 10004 \\
\hline Age & 38.26 & 3790 & 39.70 & 51.73 & 40.21 & 42,05 & 42.79 & 55.24 \\
\hline Geoder (' male')] & $54.20=$ & 48.445 & 44.262 & $44.75 x$ & 47.365 & 49,095 & 45,435 & $46.15 x$ \\
\hline Bace $[2$ whited"? & 87.615 & $7921=$ & $86.05 \%$ & 75.815 & 87002 & 74.688 & $78,02 \%$ & 6959s \\
\hline Education ( $X$ college + ) & $47,89 \mathrm{x}$ & $3125 x$ & 30832 & $12.00 \mathrm{~m}$ & 39.768 & $1987 x$ & 18.538 & $8,4 x$ \\
\hline Mace of use ( $\%$ at home) & $67,73 \times$ & 51.448 & NIA & $N / A$ & $8402 \pi$ & $6984 x$ & NiA & N/A \\
\hline Online activiny & 1.98 & 134 & NJA & $N / A$ & 3.39 & 2.53 & $N / A$ & N/A \\
\hline Use of emal & 55.072 & 36.785 & NIA & NiA & s6.11x & $7006 x$ & N/A & NiA \\
\hline
\end{tabular}

Figure 6. The Comparison of the Internet Popularizing Rate Data

\subsection{The Modern Internet Based Startups}

Mobile Internet development in our country do not have first mover advantage and the operating system with mobile chip technology, the human-computer interaction technology, mobile cloud computing technology, followed by using competition at a disadvantage in the vertical ecological layout. Especially in the mobile operating system is still the core of the intelligent terminal and the mobile Internet industry, although our country enterprise has the research and development to explore the market are conducted based on the basic Android experience of commercial innovation which has not happened since the research system. The related application service platform, application and brand terminal are relatively independent development. The development trend for the startups could be summarized as the follows. 
Improve the relevant laws and regulations and supervision mechanism and create a good environment for the mobile Internet development. Internet related laws and the regulations establish and improve the regulatory system, regulating the behavior of mobile Internet access mechanism with market competition and regulatory system to maintain the market competition and development of fair, healthy and orderly. At the same time intensify policy support to create the good policy environment conducive to the general development of mobile Internet.

$>$ Improve the network infrastructure and improve the mobile Internet penetration. The construction of the mobile Internet industry network infrastructure to meet the rapid growing mobile Internet business demand for the basic network resources; Improves performance of the mobile Internet network, optimize network structure, promote the development of integrated information exchange platform and accelerate upgrading of mobile Internet industry in China.

$>$ Accelerating technological innovation and improve general level of mobile Internet applications. Technology innovation is the key of mobile Internet industry. Increased investment in technology innovation, and improve enterprise innovation ability is the basic requirement of the mobile Internet era. The remaking traditional industry, social services in the field of application is the key point of technology innovation in the application of innovation.

This new type of the industrial chain model includes more participant makes the traditional carrier of monopoly model almost impossible. It is the new mode in the industry of mobile marketing is concerned the industrial chain of upstream and downstream cooperation pattern at the beginning of the industrial development is of great significance. This is because in the early, the mobile Internet market has not yet formed the scale effects the development of the industry needs to push through multilateral cooperation instead of competition. So during this period, network monitor and network advertising platform, network advertising platform and network media, network monitor and network advertising platform is very common.

Take the operation mode of the marketization and look from the purpose of the setting up industry investment funds to hold enterprise for a long time, but in early support enterprise innovation and the entrepreneurship. Wait for the investment enterprise growth after mature, equity value, through the equity transfer value-added investment, ensure the smooth operation of the industrial investment fund. After waiting for money back, continue to support the new enterprise, realize the benign operation. Therefore, the operation mode of the marketization of the Internet industry investment fund should be taken. At the same time, should also improve the domestic Internet industry risk investment mechanism construction, set up corresponding guarantee mechanism, insurance mechanism with relevant subsidies and preferential policy, reduce running cost and share the risk of investment to better promote the development of the Internet industry fund. In the Figure 7, we demonstrate balance and allocation of the finance suggestion for the modern Internet based high-tech enterprises. 


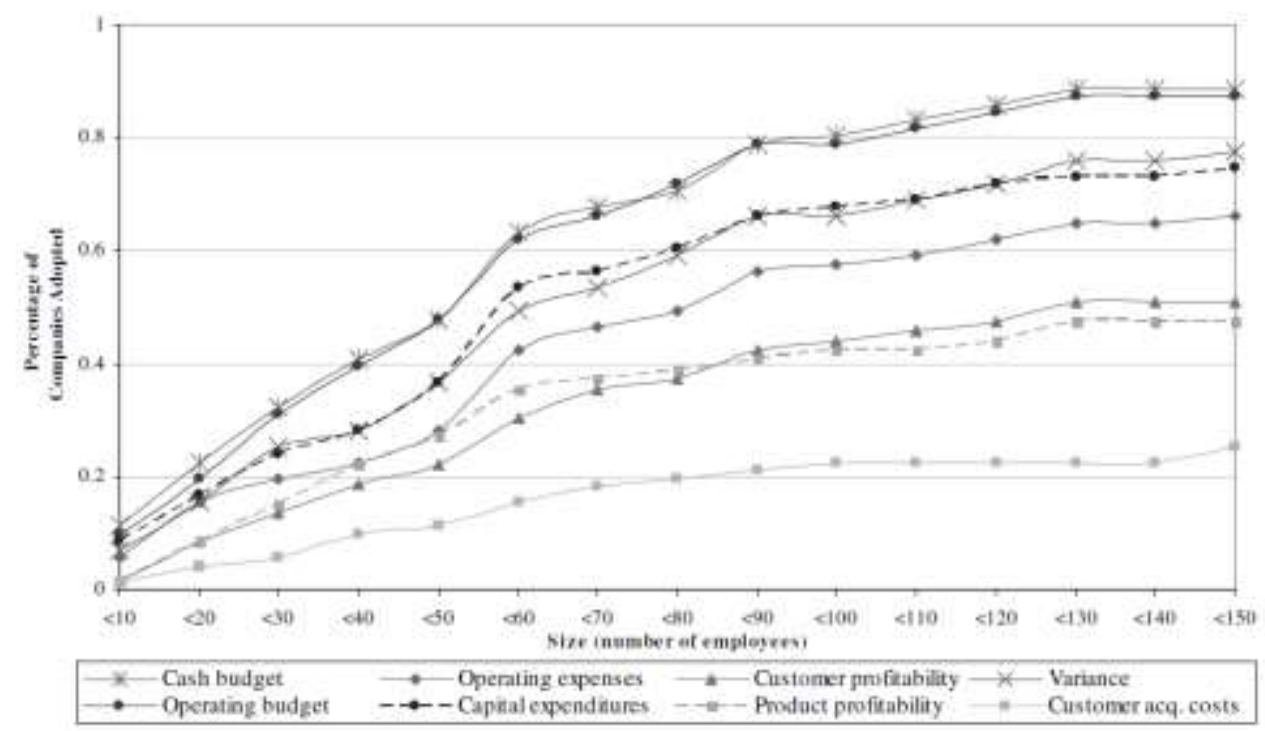

Figure 7. The Balance and Allocation of the Finance for Hightech Enterprise

Comprehensive is concerned the Internet industry development significantly affected by the Internet industry market status and the influence of the talent quality human resources reserves which reflecting the Internet industry as an emerging knowledge economy and technical and economic characteristics of needs, its development must have the high quality people. Economic development level and added value of Internet infrastructure significantly positive influence on Internet industry, they are empirically the sustained growth of the Internet industry of the economy and the basic guarantee. Research and development ability and the level of opening to the outside world for the development of the Internet industry also has a significant impact, suggests that new technology of the Internet economy and the industry development must have a lot of research and the general development investment provides impetus for its innovation. The Internet is a virtual realm of freedom without borders, the flow of information on the Internet freedom, freedom of speech, freedom of the users, users, so the openness is the most fundamental features of the Internet, the Internet's openness is not just a technical level, it also has a deeper meaning, and maintain a high level of openness is both source of Internet access to new technology industrial development make Chinese Internet companies also continue to gain foreign capital support and be able to grow.

\section{Experiment and Illustration}

In this part, we illustrate the statistical data for the proposed method. In the Figure 8, we show the statistical data of the winning enterprises. The most important factors could be show as the follows. CEO experience and the planning schedule ability, the International presence and the reputation, the core competitiveness of the enterprises. In the Figure 9, we illustrate the development of Internet usage and the popularity, we could conclude from the statistical data that the usage of the Interne and the corresponding services is growing rapidly. In the Figure 10, we demonstrate the trend of the smart home devices and the cloud computing based service platforms. In the next few years, the development of smart home will be in the speed phase, on one hand and technology of smart home related agreement standard began active exchange and fusion, on the other hand smart home industry mergers and the acquisitions phenomenon began to come out even become mainstream. Although the next few years is very fast a few years intelligent household industry development, but also most considerable period due to the housing families become the focus of various industries for the market, the smart home as a platform to undertake to become the parties to force first for the goal. The current cloud 
computing center for energy consumption increasing, a amount of resource consumption in the cooling system, so we need to re-examine programming model from the angle of energy, storage technology, data center technology such as network topology and carries on the optimization reconstruction so as to achieve the goal of energy conservation.

\begin{tabular}{|c|c|c|c|c|}
\hline \multirow[b]{2}{*}{ Dependent Variable } & \multicolumn{2}{|c|}{$\begin{array}{c}\text { First Stage } \\
\text { Time-to-Hiring a Financial } \\
\text { Manager } \\
\end{array}$} & \multicolumn{2}{|c|}{$\begin{array}{l}\text { Second Stage } \\
\text { Time-to-Adoption of } \\
\text { Operating Budgets }\end{array}$} \\
\hline & $\begin{array}{c}\text { Hazard } \\
\text { Ratio }\end{array}$ & $\begin{array}{c}\text { Robust } \\
\text { Std. Error }\end{array}$ & $\begin{array}{c}\text { Hazard } \\
\text { Ratio }\end{array}$ & $\begin{array}{c}\text { Robust } \\
\text { Std. Error }\end{array}$ \\
\hline Biotechnology & & & 2.307 & (1.933) \\
\hline Information tech. & & & 1.438 & $(1.045)$ \\
\hline Employees & $1.015^{t a t}$ & $(0.002)$ & $1,021^{* *}$ & $(0.008)$ \\
\hline Venture funding & $3.635^{* 04}$ & $(1.086)$ & $5.415^{\circ}$ & $(4.866)$ \\
\hline Founder replaced & 0.770 & $(0.241)$ & 1.156 & $(0.409)$ \\
\hline CEO experience & $1.028^{*}$ & $(0.017)$ & $1.061^{k \neq}$ & (0.032) \\
\hline CEO planning beliefs & $2.336^{* *}$ & $(0.871)$ & $6.020^{2 \neq}$ & (4.558) \\
\hline International presence & 1.100 & $(0,348)$ & 1.311 & $(0.392)$ \\
\hline Systems infrastructure & $0.599 * *$ & $(0,122)$ & & \\
\hline $\begin{array}{l}\text { Predicted hazard rate to hire } \\
\text { a financial manager }\end{array}$ & & & 0.430 & $(0.256)$ \\
\hline Number of obs. & 202 & & 177 & \\
\hline Number of compunies & 68 & & 68 & \\
\hline Chi-square & $99.27^{*+1}$ & & $29.31=* 4$ & \\
\hline
\end{tabular}

Figure 8. The Statistical Data of the Winning Enterprises

\begin{tabular}{|c|c|c|c|c|c|c|c|}
\hline & $\begin{array}{l}\text { Nowember } \\
\text { 1994 }\end{array}$ & $\begin{array}{l}\text { Qavober } \\
\text { rog? }\end{array}$ & $\begin{array}{l}\text { Sepermber } \\
1998\end{array}$ & $\begin{array}{l}\text { Auguat } \\
2000\end{array}$ & $\begin{array}{l}\text { Sppumber } \\
2001\end{array}$ & $\begin{array}{l}\text { Occuber } \\
2003\end{array}$ & $\begin{array}{l}\text { October } \\
2007\end{array}$ \\
\hline $\begin{array}{l}\text { Conputer use at waik } \\
\text { (11-yes) }\end{array}$ & $\mathrm{N} / \mathrm{A}$ & $1.445^{t+1}$ & $N / A$ & $\mathrm{~N} / \mathrm{A}$ & $2037^{-1-}$ & $2.059^{\prime \prime}$ & N/A \\
\hline$A B$ & $0.024^{\prime \prime \prime}$ & $0.028^{\prime \prime}$ & $\cos s^{2}$ & $0.032^{21}$ & $0.039^{-1}$ & $0.0 \pi^{2+}$ & a.035" \\
\hline Gender (Evele - 1) & $0.254^{*-}$ & 0.496 & 0.111 & 0.026 & 0.092 & -0.018 & -0.01 \\
\hline Metuopolitan (yes - 1 ) & $0,6003^{\prime \prime}$ & $0210^{\circ}$ & a.13it & 0.056 & 0217 & 0.115 & $0.240^{\circ}$ \\
\hline Colleze studen (ves - 1 ) & $0.615^{1+2}$ & $1355^{14}$ & $1254^{1+}$ & $0.780:-$ & $1384+$ & $1.460^{\prime \prime}$ & $0786+$ \\
\hline Eamings (logzed) & $0.14 \mathrm{r}^{\mathrm{N}}$ & $a 100^{\circ}$ & $0266 \div$ & $0.161^{2 *}$ & 0.048 & -onst & $0270^{\circ}$ \\
\hline Married (yes-1) & $0.415^{\circ}$ & 0.092 & na1 & $0.201^{-1+}$ & $0.330^{--}$ & $0.336^{6}$ & $0312^{+\prime}$ \\
\hline \multicolumn{8}{|l|}{ Beyian" } \\
\hline West & 0.230 & $0.180^{\circ}$ & $020 t^{\prime+}$ & $0.272^{2 *}$ & o. $193^{+}$ & $0.323^{+1+}$ & $0.0329^{*}$ \\
\hline Midwest & -0.127 & anis. & $0.150^{-2}$ & $0.162^{\circ}$ & 0084 & 0.101 & $0.214^{10}$ \\
\hline Nontheast & -0.152 & $-0,009$ & -0005 & $0.221^{-1 *}$ & $0271^{\prime *}$ & $0.245^{+14}$ & $0.140^{\circ}$ \\
\hline \multicolumn{8}{|l|}{ Suluratiotr } \\
\hline tess thie high school & $-\left[.404^{\prime \prime \prime}\right.$ & $-0.885^{\prime \prime}$ & $-1,301^{\prime \prime \prime}$ & -1.708 & $-1554^{\prime+}$ & $-1924^{\prime \prime}$ & $-2 \pi 13^{211}$ \\
\hline Wigh school & $-1.366^{614}$ & $-1.473^{12}$ & -1.346 .1 & $-1468^{2 *}$ & $-1 A 78$ & $-1.62 y^{-}$ & $-1.520^{3 .}$ \\
\hline Some colleze & $-0.794^{211}$ & $-0.007^{3+1}$ & $-0.761^{21}$ & $-a 794^{\prime \prime}$ & $-\cos \pi^{2}$ & $0890^{\circ 1}$ & $-a 766^{2+1}$ \\
\hline Collest & $0.347^{\circ}$ & $0.57^{\circ}$ & $-0.242^{\prime \prime}$ & $0.330^{-1}$ & $-02 \pi i^{\circ}$ & 0.376 & $-0399^{\prime \prime}$ \\
\hline \multicolumn{8}{|l|}{ Mace" } \\
\hline Afrian American & $0.560^{\prime \prime \prime}$ & 0669 & $-0782=$ & 0.904 & - $086 \pi^{-7}$ & $-0.896^{\circ}$ & $-0.985^{\circ}$ \\
\hline IEspanic & - $.798^{-1}$ & -0.956 & $-1,02 y^{2+1}$ & -1.228 & $-12 \pi 1^{+t}$ & $-1.299^{\circ}$ & $-1349^{\prime \prime}$ \\
\hline other: & $-0,367$ & a.491- & $-031^{-}$ & $0.725^{\circ}$ & $-0 \operatorname{sen} "$ & $-0.482^{2}$ & $-0.57{ }^{\prime \prime}$ \\
\hline \multicolumn{8}{|l|}{ Oxtrpoben: } \\
\hline Tecturial/sules,derical & $0.258^{-}$ & $0.390^{-1-}$ & $0.354^{20+}$ & $0355^{\circ}$ & $-02 \pi \pi^{10}$ & $-0.210^{\circ}$ & $-0270^{\circ+}$ \\
\hline service & $0.473^{\cdots}$ & $0.625^{-}$ & -1065 & $-1.000^{2 .}$ & $-04 z^{-1}$ & astar & a.914. \\
\hline Blue cultar & - $0599^{\prime \prime}$ & $-0900^{-}$ & $-1,197$ & $-1.197^{\circ}$ & $-0738^{-1}$ & $-0.541^{-1}$ & -1.166 \\
\hline AEriculture & 0.759 & a.6. & -1.198 & $-1461^{2}$ & $06 \pi$ & -1.299 & $-1.293^{\prime \prime}$ \\
\hline$-2 \mathrm{~kg}$ likelihood (De) & $6913\{20\}$ & $12.161(21)$ & $14595(20)$ & $14854[20]$ & 13,408 (21) & ttsol (21) & $12.865(20)$ \\
\hline $\mathrm{N}$ & 24,154 & 13,0ss: & 12965 & $13,361$. & 15,428 & 15040 & 14,719 \\
\hline
\end{tabular}

Figure 9. The Development of Internet Usage and Popularity 


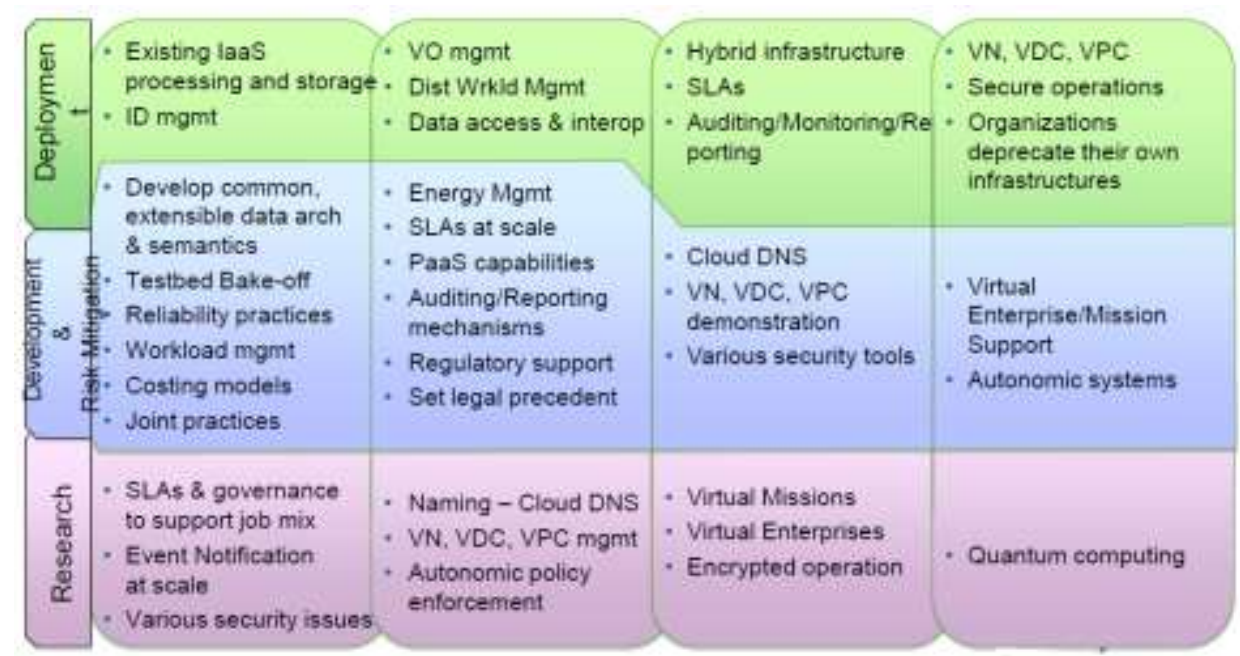

Figure 10. The Trend of the Smart and Cloud Based Platforms

\section{Conclusion and Future Work}

We conduct analysis on the development of modern smart home industry and cloud computing technique with the influence on transforming the Internet startup orientation in this research article. The primary research down in the article could be summarized as the follows. (1) We review the state-of-the-art smart home systems. Smart home controller is the core of the whole system as the family gateway to connect the internal network and external network and provide the function of remote monitoring for the extranet. The smart home techniques are popularly adopted by the recent startups. (2) We summarize the core techniques of the cloud computing platforms and services. Cloud computing applications are in a lot of unique distribution and the gathering data to make the traditional TCP protocol data congestion can occur easily. The use of cloud computing will enhance the efficiency of the companies. (3) We analyzed the transformation of startup orientation with high-tech elements. New Internet communication will be different from the traditional communications applications which have the richer connotation to realize the integration of communication. In summary, the rapid and fast development will help the companies to gain more wealth. In the recent future, we will do more research on the new developed techniques to help propose more applicable uses.

\section{References}

[1] S. Schneppe, M. D. Namiot, A. Maximenko and D. Malov, "Wired Smart Home: energy metering, security, and emergency issues", In Ultra-Modern Telecommunications and Control Systems and Workshops (ICUMT), 2012 4th International Congress on, IEEE, (2012), pp. 405-410.

[2] C. Xiaodao, T. Wei and S. Hu, "Uncertainty-aware household appliance scheduling considering dynamic electricity pricing in smart home", Smart Grid, IEEE Transactions on, vol. 4, no. 2, (2013), pp. 932-941.

[3] L. C. Chun, C. H. Yang and J. Z. Shyua, "A comparison of innovation policy in the smart grid industry across the pacific: China and the USA", Energy Policy, vol. 57, (2013), pp. 119-132.

[4] Z. Xun, Z. F. Xu and M. D. Hu, "The development for Internet of Things smart home service operation support platform", In Applied Mechanics and Materials, vol. 507, (2014).

[5] S. H. Ching, Y. C. Huang, C. M. Huang and C. C. Tung, "Energy Management Technologies for Smart Home Applications", In Proceedings of the 2nd International Conference on Intelligent Technologies and Engineering Systems (ICITES2013), Springer International Publishing, (2014), pp. 659-665.

[6] K. B. Jae, Y. S. Park and S. H. Yang, "Microcontroller Implementation of Rule-based Inference System for Smart Home", International Journal of Smart Home, vol. 8, no. 6, (2014), pp. 197-204.

[7] P. Peter and D. Dietrich, "Demand side management: Demand response, intelligent energy systems, and smart loads", Industrial Informatics, IEEE Transactions on, vol. 7, no. 3, (2011), pp. 381-388. 
[8] C. Shanzhi, H. Xu, D. Liu, B. Hu and H. Wang, "A vision of IoT: Applications, challenges, and opportunities with china perspective", Internet of Things Journal, IEEE, vol. 1, no. 4, (2014), pp. 349359.

[9] B. Anton, J. Abawajy and R. Buyya, "Energy-aware resource allocation heuristics for efficient management of data centers for cloud computing", Future generation computer systems, vol. 28, no. 5, (2012), pp. 755-768.

[10] A. Z. Mohammed, B. Soh and E. Pardede, "A new approach using redundancy technique to improve security in cloud computing”, In Cyber Security, Cyber Warfare and Digital Forensic (CyberSec), 2012 International Conference on, IEEE, (2012), pp. 230-235.

[11] W. Qian, C. Wang, K. Ren, W. Lou and J. Li, "Enabling public auditability and data dynamics for storage security in cloud computing", Parallel and Distributed Systems, IEEE Transactions on, vol. 22, no. 5, (2011), pp. 847-859.

[12] E. Daji, G. Kou, Y. Peng, Y. Shi and Y. Shi, "The analytic hierarchy process: task scheduling and resource allocation in cloud computing environment", The Journal of Supercomputing, vol. 64, no. 3, (2013), pp. 835-848.

[13] M. S. Chandra and A. Mondal, "Identification of a company's suitability for the adoption of cloud computing and modelling its corresponding Return on Investment", Mathematical and Computer Modelling, vol. 53, no. 3, (2011), pp. 504-521.

[14] R. Mustafizur, R. Hassan, R. Ranjan and R. Buyya, "Adaptive workflow scheduling for dynamic grid and cloud computing environment", Concurrency and Computation: Practice and Experience, vol. 25, no. 13, (2013), pp. 1816-1842.

[15] B. Dario, "A stochastic model to investigate data center performance and qos in iaas cloud computing systems", Parallel and Distributed Systems, IEEE Transactions on, vol. 25, no. 3, (2014), pp. 560-569.

[16] T. J. Tsong, J. C. Fang and J. H. Chou, "Optimized task scheduling and resource allocation on cloud computing environment using improved differential evolution algorithm", Computers \& Operations Research, vol. 40, no. 12, (2013), pp. 3045-3055.

[17] Z. Sonya, "A Technology-Business-Environment Model for Effective Internet Entrepreneurship Education”, In Information Technology-New Generations (ITNG), 2015 12th International Conference on, IEEE, (2015), pp. 632-637.

[18] W. G. Alexander, J. Perepelkin, D. D. Zhang and M. A. Vachon, "Market orientation, alliance orientation, and business performance in the biotechnology industry", Journal of Commercial Biotechnology, vol. 20, no. 2, (2014).

[19] T. J. Philippe, A. Castiaux, Y. Truong, G. A. Athaide and R. R. Klink, "The effect of market-pull vs. resource-push orientation on performance when entering new markets", Journal of Business Research, (2015). 
International Journal of Multimedia and Ubiquitous Engineering

Vol.12, No.1 (2017) 